\title{
Mapeamento da inclusão produtiva na assistência social na cidade do Rio de Janeiro
}

\author{
Mapping productive inclusion in social assistance in the city of Rio de Janeiro \\ Mapeo de inclusión productiva en asistencia social en la ciudad de Río de Janeiro
}

Recebido: 19/11/2021 | Revisado: 25/11/2021 | Aceito: 26/11/2021 | Publicado: 09/12/2021

\author{
Vânia de Cássia de Araujo Dutra \\ ORCID: https://orcid.org/0000-0001-9377-7342 \\ Universidade de Vassouras, Brasil \\ E-mail: vania.dutra@universidadedevassouras.edu.br
}

\begin{abstract}
Resumo
Este artigo apresenta o resultado da pesquisa de estágio pós-doutoral no Programa de História das Ciências e da Saúde da Casa Oswaldo Cruz: História das Políticas, Instituições e Profissões em Saúde. Nas pesquisas empírica e documental conhecemos sobre às duas últimas décadas de trajetória da inclusão produtiva na Secretaria Municipal de Assistência Social na Prefeitura do Rio de Janeiro. O objetivo deste artigo é apresentar o resultado de parcial da pesquisa de mapeamento de demandas e oportunidades na periferia e favelas da cidade do Rio de Janeiro, sob a ótica do Centro de Referência de Assistência Social da Cidade do Rio de Janeiro (CRAS). Os objetivos deste mapeamento foram identificar e mapear os principais eixos de atividade econômica e os cursos de qualificação profissional mais procurados pelas famílias e sujeitos sociais assistidos no Sistema Único de Assistência Social no município do Rio de Janeiro. A pesquisa aplicada foi realizada através de formulário virtual e aplicada em 30 CRAS, sem identificação pessoal do preenchimento do formulário conforme normativa para formação de banco de dados através do endereço eletrônico institucional de cada equipamento. Apresentamos os principais resultados deste mapeamento e o curso de qualificação profissional mais procurado no eixo ambiente e saúde conforme quarta edição do catálogo nacional de cursos de técnicos e de formação inicial continuada do Ministério da Educação no ano de 2020.
\end{abstract}

Palavras-chave: Assistência social; Política social; Trabalho.

\begin{abstract}
This article presents the results of post-doctoral internship research in the History of Science and Health Program at Casa Oswaldo Cruz: History of Health Policies, Institutions and Professions. In empirical and documentary research, we know about the last two decades of trajectory of productive inclusion in the Municipal Department of Social Assistance in the City of Rio de Janeiro. The aim of this article is to present the result of a partial survey on the mapping of demands and opportunities in the periphery and slums of the city of Rio de Janeiro, from the perspective of the Reference Center for Social Assistance (CRAS) of the City of Rio de Janeiro. The objectives of this mapping were to identify and map the main axes of economic activity and the professional qualification courses most sought after by families and social subjects assisted by the Unified Social Assistance System in the municipality of Rio de Janeiro. The applied research was carried out through a virtual form and applied to 30 centers, without personal identification of filling out the form as per the regulations for the formation of a database through the institutional email address of each equipment. We present the main results of this mapping and the most sought after professional qualification course in the environment and health axis, according to the fourth edition of the national catalog of technical courses and continuing initial training of the Ministry of Education in 2020.
\end{abstract}

Keywords: Social assistance; Social policy; Work.

\section{Resumen}

Este artículo se presentan los resultados de la investigación de la pasantía postdoctoral en el Programa de Historia de la Ciencia y la Salud de Casa Oswaldo Cruz: Historia de las Políticas, Instituciones y Profesiones de Salud. En la investigación empírica y documental conocemos las últimas dos décadas de trayectoria de inclusión productiva en el Departamento Municipal de Asistencia Social de la Ciudad de Río de Janeiro. El objetivo de este artículo es presentar el resultado de una encuesta parcial sobre el mapeo de demandas y oportunidades en la periferia y favelas de la ciudad de Río de Janeiro, desde la perspectiva del Centro de Referencia de Asistencia Social de la Ciudad de Río de Janeiro. Los objetivos de este mapeo fueron identificar y mapear los principales ejes de la actividad económica y los cursos de calificación profesional más buscados por las familias y sujetos sociales atendidos por el Sistema Único de Asistencia Social en el municipio de Río de Janeiro. La investigación aplicada se realizó a través de un formulario virtual y se aplicó a 30 Centros de Referencia de Asistencia Social, sin identificación personal al completar el formulario de acuerdo con la normativa para la formación de una base de datos a través de la dirección electrónica institucional de cada equipo. Principales resultados de este mapeo y del curso de cualificación profesional más cotizado en el eje medio ambiente y salud según la cuarta edición del catálogo nacional de cursos técnicos y formación inicial continua del Ministerio de Educación en 2020.

Palabras clave: Asistencia social; Politica social; Trabajo. 


\section{Introdução}

O marco temporal de estudo pós-doutoral no Programa de História das Ciências e da Saúde da Casa Oswaldo Cruz, na linha de pesquisa História das Políticas, Instituições e Profissões em Saúde está circunscrito nas duas últimas décadas, ou seja, o período de 2000 a 2020, onde foi possível conhecer a trajetória da inclusão produtiva na Secretaria Municipal de Assistência Social na Prefeitura do Rio de Janeiro. Todavia objetiva-se neste artigo apresentar o resultado da pesquisa de mapeamento de demandas e oportunidades na periferia e favelas da cidade do Rio de Janeiro. Temos o pressuposto que para realizar uma programação efetiva de inclusão produtiva, um dos elementos primordiais seria identificar as principais necessidades sociais a partir de uma escuta qualificada da população que frequentam os serviços prestados no Centro de Referência de Assistência Social (CRAS).

Sendo o CRAS uma unidade da rede socioassistencial de proteção social básica com função específica de oferta de serviços e ações de trabalho social com famílias, e de gestão territorial da rede socioassistencial, torna-se muito importante conhecer as necessidades que chegam até as equipes de atendimento direto e contínuo, principalmente, no tocante a qualificação profissional porque nestas atividades que os trabalhadores, os informais, os desempregados e desalentados buscam diversas orientações sobre inserção no mundo do trabalho para geração de renda.

Portanto, o mapeamento de oportunidades e demandas de inclusão produtiva na assistência social sob a ótica dos do serviço de atendimento visa contribuir, principalmente no pós-pandemia COVID 19, para organização de cursos de qualificação profissional para o público-alvo da assistência social.

Nesta comunicação oral apontaremos o curso qualificação profissional mais procurado no eixo ambiente e saúde. A escolha do eixo ambiente e saúde não foi de forma aleatória, a escolha surgiu do mapeamento realizado por meio de formulário eletrônico. O Formulário foi criado com base no Catálogo Nacional de Curso de Técnicos e Cursos de Formação Inicial do Ministério da Educação (2020) são 14 eixos tecnológicos ${ }^{1}$ de cursos FIC, a saber: “Ambiente e Saúde, Controle e Processos Industriais, Desenvolvimento Educacional e Social, Gestão e Negócios, Informação e Comunicação, Infraestrutura, Produção Alimentícia, Produção Cultural e Desing, Produção Industrial, Recursos Naturais, Segurança, Turismo, Hospitalidade e lazer. " Para uma programação efetiva de cursos de qualificação profissional considera-se muito importante identificar os cursos mais desejados pelos moradores de periferia e favelas, com os mais procurados nos territórios periféricos, a partir de informações dos equipamentos de assistência social, que lidam com a procura de famílias acompanhadas Programa de Atenção Integral às Famílias, ou na demanda espontânea para a realização do Cadastro Único do Programa Sociais do Governo Federal.

\section{Metodologia}

A pesquisa aplicada foi de forma remota durante o período de isolamento e distanciamento social requeridos pela Pandemia COVID -19. 1. Para elaboração do roteiro de mapeamento de oportunidades e demandas usamos os 14 eixos tecnológicos para cursos de Formação Inicial do Ministério da Educação, conforme já mencionado anteriormente. O objetivo foi identificar através da aplicação do formulário nos 47 CRAS, para tanto usou-se survey Google doc., sem identificação pessoal para o preenchimento segundo normativa para formação de banco de dados' conforme a Lei Geral de Proteção de Dados (Brasil, 2018). Também neste período realizou-se uma revisão bibliográfica na área de sociologia urbana, com particularidade na temática das favelas cariocas, nos seguintes autores Alvito e Zaluar (2004); Leeds e Cavalcanti (2018); Lima e Viana (2018); Machado et al. (2018) e Valladares (2005).

No mês de setembro de 2020, o formulário eletrônico foi enviado para os e-mails institucionais de cada CRAS, com autorização da Gerência de Educação Permanente da Secretaria Municipal de Assistência Social. No teor do e-mail 
institucional explicou-se que formulário era um instrumento da pesquisa de pós-doutorado e tinha por objetivo identificar e mapear as demandas e oportunidade de inclusão produtiva do CRAS, já que é neste serviço que as famílias são acompanhadas em territórios periféricos e de favelas na cidade do Rio de Janeiro. Este mapeamento contribuiria para aproximar a programação da inclusiva produtiva dos moradores, que procuram sempre um curso de qualificação profissional e/ou forma de inserção no mundo de trabalho a fim de gerar renda para sua própria sobrevivência e de seus familiares.

Mesmo assim, enfrentou-se algumas dificuldades na adesão de respostas, dentre os 47 formulários encaminhados recebemos a resposta de 30 CRAS. Numa sondagem como pesquisadora observadora na pasta da secretaria foi possível estimar alguns dos motivos de 17 CRAS não responderem a pesquisa, ou porque os equipamentos estavam com novos gestores recém-chegados ao território e/ou porque não tinham conhecimento da temática de inclusão produtiva, ou por excesso de trabalho burocráticos no período em decorrência de acompanhamento de planilhas das pessoas que tiveram suspenso o auxílio emergencial; ou processo de eleição municipal, já que mesmo com a carta de recomendação da Secretaria Municipal de Assistência Social e antes do período eleitoral, alguns gestores fizeram a vinculação com este momento político da cidade e não responderam o formulário.

Diante das situações supramencionadas avaliou-se como satisfatório as repostas de 30 CRAS, um quantitativo expressivo para seguimento da análise, já que temos uma amostra de $65 \%$ de $100 \%$ que se tinha a expectativa de efetivar a pesquisa, ou seja em termos uma representatividade para objetivo de identificar a visão dos serviços no território no qual trabalham sobre demandas e oportunidades de inclusão produtiva para o público em acompanhamento sistemático amostra colhida é válida. Cabe ainda informar que sobre a temática do trabalho do assistente social nas favelas leu-se o texto de Honorato (2012), sobre assistência social Boschetti (2006) e inclusão produtiva as obras de Souza (2013) e Dutra (2016).

\section{Resultados e Discussão}

O Programa Nacional de Promoção do Acesso ao Mundo do Trabalho - ACESSUAS-TRABALHO, Resolução No 18, de 24 de maio de 2012, objetiva promover a integração dos usuários da assistência social ao mundo do trabalho, por meio de ações articuladas e mobilização social nas cidades do Brasil. Este programa busca autonomia dos sujeitos sociais da Política de Assistência Social, por meio do incentivo e da mobilização à integração ao mundo do trabalho e também foi executado no Município do Rio de Janeiro.

O referido programa propõe o desenvolvimento de ações de articulação, mobilização e encaminhamento de pessoas em situação de vulnerabilidade social com vistas assegurar e/ou possibilitar inserção no mundo do trabalho, com a viabilização de cursos de qualificação profissional, atividades de inclusão produtiva e serviços de intermediação de mão- de-obra. Incluem ainda, ações de articulação com outras políticas públicas para superação da situação de miséria e pobreza.

No levantamento em banco de dados oficiais no ano de 2020 verificou-se o seguinte quantitativo de famílias cadastradas no CRAS 28.875.190, em situação de extrema pobreza 39.596.469. ${ }^{2}$ O Programa Nacional de Promoção do Acesso ao Mundo do Trabalho - ACESSUAS Trabalho disponível da quantia de R \$2.940.000,00 para a proteção básica desenvolver os programas nos CRAS. Estes dados nos informam a importância de execução de programas de inclusão produtiva nos territórios para geração de rendas e desenvolvimento de capacidades locais.

A Inclusão Produtiva e Dinâmicas de Desenvolvimento Econômico Local - visa à mobilização das capacidades sociais e produtivas da população em situação de extrema pobreza nos territórios com baixos índices de desenvolvimento humano e social.

\footnotetext{
2 https://aplicacoes.mds.gov.br/sagi/ri/relatorios/cidadania/\#equipamentossuas
} 
Na tabela 1 - As principais atividades econômicas no território do Centro de Referência de Assistência Social verifica-se a percepção do CRAS acerca das atividades econômicas desenvolvidas nos territórios que são as seguintes: Comércio no território, Trabalho Informal, Serviço Público e Serviços. Todas as atividades do setor terciário.

Tabela 1 - As principais atividades econômicas no território do Centro de Referência de Assistência Social.

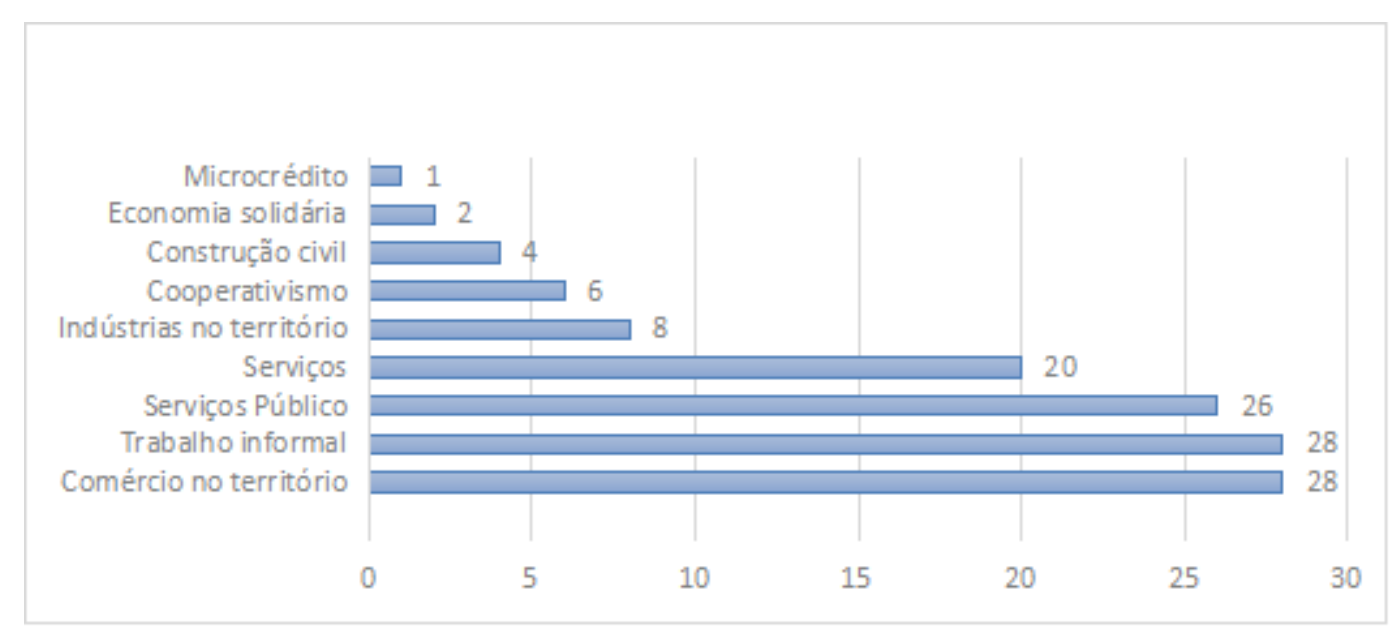

Fonte: Dutra (2020), Mapeamento de Demandas de Oportunidades nos CRAS.

Pode-se inferir que a percepção dos CRAS de seus territórios em relação atividade econômica empata entre o trabalho informal e comércio território. Isto indica o alto grau de consumo dos moradores dos territórios, que em sua maioria são compostos por favelas. Seguido pelos Serviços Públicos (escolas, postos de saúde, equipamentos de assistência social).

Neste sentido também se observa que temos uma baixa percepção das indústrias nos territórios, que nos leva a ponderar sobre o processo de desindustrialização (Harvey,2013) sofrido na cidade do Rio de Janeiro. Este ponto é importante, porque não podemos responsabilizar os indivíduos por sua situação de pobreza, desemprego e de trabalho informal. Porque temos o desafio de pensar um projeto político econômico para o Brasil, que aumente as oportunidades de trabalho e renda e reduza as desigualdades sociais.

Em estudos anteriores verifica-se que há no Brasil uma institucionalidade democrática, ou seja, temos nos dois últimos decênios os mecanismos de participação popular. Esta institucionalidade democrática, na atualidade é um campo de disputas de identidade socioeconômica, político-cultural e ambiental, neste sentido o espaço territorial, o lugar será caracterizado como uma localidade com projeto de desenvolvimento humano, deverá também ter projetos de potencialidade da economia para que seus moradores tenham condições de vida e ruptura com o ciclo vicioso da miséria e da pobreza impostas à boa parte dos moradores de favelas.

Sobre atividade econômica da construção civil que mais emprega os trabalhadores moradores de favelas, a paralisação de lançamentos de construções habitacionais e das obras públicas teve uma queda e lançando mais trabalhadores no ramo informal.

O setor terciário foi o que mais apareceu na pesquisa, sendo neste setor que estão as atividades econômicas informais, sem recolhimento do ISS terceira atividade econômica na percepção dos CRAS está no ramo de serviços.

A questão da atividade informal é a falta de arrecadação tributária numa economia capitalista, que desfavorece não só as políticas de distribuição de renda, mas demonstra que são atividades sem perspectiva de crescimento econômico, pois não surgem empresas, denota que são atividades econômicas voltadas para sobrevivência e subsistência. São também atividades com baixa sofisticação tecnológica, baixa escolaridade, são serviços escaláveis e de prestação de serviços por determinado tempo. (Silva,2008) 
No que tange a proteção social do trabalhador informal está desprotegido ele e sua família se adoecer ou vier a falecer, porque não tem direito ao auxílio-doença, pensão e aposentadoria, que traz para assistência social um número expressivo de trabalhadores informais ao completar a idade de 65 anos e acessarem ao Benefício da Prestação Continuada.

Diante da Pandemia COVID 19 optou-se por apresentar a análise do eixo tecnológico ambiente e saúde. Conforme escrito no catálogo nacional de cursos de tecnologia, de forma resumida, o eixo ambiente e saúde ${ }^{3}$ contempla atividades coordenadas de proteção e preservação dos seres vivos e de cuidado o meio ambiente, de segurança individual e comunitária, de gerenciamento e avaliação de risco, projetos de educação ambiental; de suporte contínuo aos profissionais no cuidado e atenção da saúde.

Nosso foco nesta análise são os cursos de formação inicial continuada, direcionados jovens, adultos e idosos que buscam qualificação para o desenvolvimento de habilidades e as competências para empreender uma carreira profissional, mesmo com a escolaridade de ensino fundamental ou ensino médio, desta forma ter uma vida produtiva e social com ferramentas para gerir sua própria sobrevivência e romper com o círculo vicioso da miséria imposta na sociedade capitalista.

Com o objetivo de mapear os cursos de qualificação profissional na área de Ambiente e Saúde no formulário solicitase que indicassem os cursos de formação inicial continuada (FIC) preferenciais do público atendido no CRAS, o resultado disponível na Tabela 2 - Cursos de Qualificação Profissional Ambiente e Saúde. É possível verificar que os cursos de Cuidador de Idoso e Cuidador Infantil foram indicados por 26 CRAS.

Tabela 2 - Cursos de Qualificação Profissional Ambiente e Saúde.

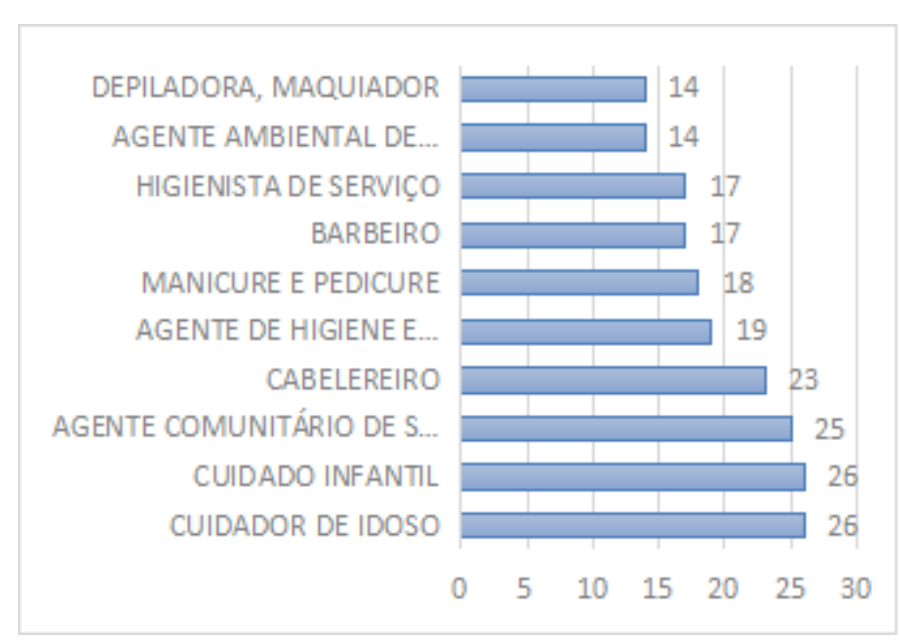

Fonte: Dutra (2020), Mapeamento de Demandas de Oportunidades nos CRAS.

Desta escolha pode-se considerar que o aumento de interesse sobre o curso de cuidador de idoso e/ou cuidador infantil principalmente no período da Pandemia COVID 19 estar diretamente relacionado ao fato de que foram as pessoas idosas e as crianças quem mais necessitaram de cuidado no âmbito familiar nas fases de isolamento e distanciamento social, medidas de prevenção e controle da infecção causada pelo novo Coronavírus (2019-nCoV) executadas no Brasil pelos governos estaduais e municipais durante o ano de 2020.

Este período de Pandemia COVID, caracterizado por uma agudização das expressões da questão social que atingiu principalmente a população em situação de pobreza e de miséria. Em relação com as crianças, principalmente as que moram nas periferias e favelas com escolas e creches públicas fechadas, sem acesso à internet para as atividades escolares, sem a merenda escolar, muitas famílias que se sustentam do trabalho informal no comércio ficaram em situação de penúria.

\footnotetext{
${ }^{3}$ Eixo tecnológico ambiente e saúde ver http://portal.mec.gov.br/setec/arquivos/pdf/eixo_13_ambiente.pdf
} 
E concomitante a estas situações de aprofundamento da desigualdade social enfrenta-se também nos territórios periféricos e de favelas a ausência de uma rede de serviços de convivência para as pessoas idosas, a literatura específica da área informa que os idosos brasileiros vivem com comorbidades, tais como por exemplo diabetes e hipertensão, e tiveram que ficar isolados. Nesta situação o Serviço de Fortalecimento de Vínculos oferecidos no CRAS também foram suspensos. Diante desta situação constata-se a necessidade de formação de cuidadores, tanto de crianças quanto de pessoas idosas. E a urgência de retornar a agenda de um outro mundo possível, principalmente com a efetivação de um pacto global de consecução dos Objetivos de Desenvolvimento Sustentável.

Neste cenário pandêmico se recoloca na agenda pública do país as estratégias do Objetivos para o desenvolvimento Sustentável (ODS) ${ }^{4}$ até ano de 2030. Importante citar que a cúpula da Organização das Nações Unidas (ONU), em reunião no período de 25 a 27 de setembro de 2015, composta por 150 países deliberam sobre a urgência de transformar o nosso mundo para as pessoas e para o planeta e estabeleceram os ODS são objetivos norteadores de políticas internacionais, nacionais e de atividades empresariais e governamental; de caráter social, econômico e ambiental a serem alcançados pelos países do mundo todo até 2030. (Dutra, 2016)

Os ODS entraram em vigor no dia $1^{\circ}$ de janeiro de 2016. Os 17 Objetivos envolvem temáticas diversificadas, como erradicação da pobreza, segurança alimentar e agricultura, saúde, educação, igualdade de gênero, redução das desigualdades, energia, água e saneamento, padrões sustentáveis de produção e de consumo, mudança do clima, cidades sustentáveis, proteção e uso sustentável dos oceanos e dos ecossistemas terrestres, crescimento econômico inclusivo, infraestrutura e industrialização, governança, e meios de implementação. ${ }^{5}$

Neste sentido as indústrias e empresas devem conhecer e entender como e de que forma os ODS influenciam e funcionam como determinantes para os negócios, que escolham desenvolverem a sustentabilidade como estratégia de suas relações econômicas.

Pondera-se que as relações econômicas são sempre relações sociais; portanto deveriam ser movidas por outra ética, que não a da busca desenfreada pelo lucro destruidor tanto dos seres humanos, quanto da natureza. Ou seja, a transição para o desenvolvimento sustentável deveria garantir a liberdade política e os direitos sociais, atravessado por uma mobilização coletiva que culmine com a organização da proteção social e seguridade social, na perspectiva de direito humano e de políticas públicas promotoras de trabalho decente, ou seja promotora de vida.

Sobre esta outra ética enfatizamos a ética do trabalho e precisamente a ética do humano, do saber cuidar. Neste contexto a formação de cuidadores através de um curso de cuidador é uma estratégia também de desenvolvimento sustentável. $\mathrm{O}$ curso de cuidador é um curso de formação inicial continuada para um segmento populacional com ensino fundamental completo. Este segmento populacional possa conseguir sua inserção no mundo do trabalho com vistas a geração de renda, ao mesmo tempo contribua para o fortalecimento de uma rede socioassistencial familiar e comunitária.

A formação de cuidadores está estritamente vinculada as desigualdades sociais e regionais de nosso país, pois ainda sofremos com baixa cobertura de rede socioassistencial e de saúde para lidar e tratar as pessoas humanas, a incapacidade muitas vezes dos familiares no trato e cuidado com criança, a pessoa idosa, e a pessoa com deficiência ${ }^{6}$.

Pode-se afirmar que a profissão de cuidador, na atualidade, é imprescindível para que os familiares e a comunidade possam desenvolver suas atividades no mundo do trabalho de forma tranquila ao saber que seu familiar está sob o cuidado de um profissional qualificado e a partir do cuidado integral e observação dos direitos sociais e humanos.

O curso de Cuidador visa contribuir para a formação de profissionais a partir do desenvolvimento de habilidade, competências e atitudes no trato com a pessoa da humana. Por conseguinte, seria muito importante que o curso de cuidador

\footnotetext{
${ }^{4}$ Sobre os Objetivos de Desenvolvimento Sustentável ver https://brasil.un.org/pt-br/sdgs

${ }^{5}$ Para saber mais detalhes sobre os 17 ODS acessar site https://brasil.un.org/pt-br/sdgs

${ }^{6}$ Sobre o conceito de pessoa com deficiência ver Araújo (2009).
} 
fosse ampliado e no seu teor apresentem os temas do desenvolvimento infanto-juvenil, a Leis Brasileira da pessoa com deficiência e aspectos do envelhecimento e o cuidado com a pessoa idosa.

$\mathrm{O}$ tema do desenvolvimento infanto-juvenil, tem como prioridade apresentar as questões pertinentes a primeira infância, pois com a entrada da mulher no mercado de trabalho e o direito a educação infantil cresce o espaço para de assistência à criança de 0 a 6 anos de idade.

O curso de cuidador deveria ser uma formação pautadas da defesa, proteção e cuidado da pessoa com deficiência. Entende-se, conforme a legislação ${ }^{7}$ que as pessoas com deficiência são aquelas que têm impedimentos de longo prazo de natureza física, mental, intelectual ou sensorial, os quais, em interação com diversas barreiras, podem obstruir sua participação plena e efetiva na sociedade em igualdades de condições com as demais pessoas. Conforme exposto na Lei Brasileira de Pessoa com Deficiência (2015), conhecer os direitos da pessoa com deficiência é o primeiro passo para que eles sejam efetivados e respeitados e promover pela sua dignidade inerente.

O curso de Cuidador dentro de um ciclo de projeto para promoção da saúde e da vida e da ética do cuidado, deverá ter como premissas aulas dialogadas, expositivas, com dinâmica de grupo, a partir de situações problemas a fim de contribuir para que no trato da pessoa humana possa estimular a pessoa idosa na manutenção do convívio familiar e social. Para tanto ter uma equipe interdisciplinar de docentes com experiência profissional e formação acadêmica nas áreas do desenvolvimento integral da criança, de envelhecimento e saúde da pessoa idosa e/ou gerontologia, dos cuidados da pessoa com deficiência.

A metodologia do curso de cuidador composta por exposição teórica e dialogada, apoio com material impresso, exercícios e/ou dinâmicas, bem como análise de casos o desenvolvimento das atividades tendo como princípio organizativo do processo pedagógico o trabalho ontocriativo ${ }^{8}$ voltados à facilitação da aprendizagem do fazer profissional e conhecimento dos desafios do Mundo do Trabalho.

Portanto, afirma-se que o curso de cuidador no sentido amplo deveria formar um profissional que requer o ensino fundamental completo, muito procurado por moradores de favelas e periferias, portanto as instituições formadoras do curso de cuidador deveriam ter a finalidade de propiciar uma formação profissional para promover, na família, ambiente favorável à conversação com a criança, idoso e pessoa com deficiência.

Importante salientar que estes profissionais irão trabalhar com outros profissionais, com a família e com a comunidade, por conseguinte integram a rede de apoio na comunidade, e possibilita a vivência intergeracional e interseccional entre as pessoas jovens e pessoas idosas, de pessoas com deficiência, por meio de atividades grupais, como por exemplo: grupos de acompanhamento terapêutico, de atividades socioculturais, de práticas corporais/físicas e outros, às visto disso, a estimulação da participação tanto da pessoa com deficiência, quanto da pessoa idosa, ou até mesmo crianças, nas atividades coletivas devem ser pactuadas com cada um deles e descritas no plano de cuidado.

Conforme Guia prático do Cuidador do Ministério da Saúde do Brasil (2008) o profissional deve apoiar a pessoa idosa, a pessoa com deficiência na execução das atividades instrumentais de vida diária. Utilizar recursos de informação e comunicação adequados aos mesmos. Verificar a necessidade e/ou condições de órteses (bengalas, andadores etc.) e próteses dentárias, auditivas e oculares. Saber ouvir, Saber cuidar, reconhecer situações de urgência e emergência. Realizar primeiros socorros e providenciar atendimento de suporte.

No cuidado com a criança contribuir para que os envolvidos no trato e cuidado de primeira infância consiga observar e compreender a dinâmica da criança e do contexto social e familiar, entendendo sua função e o papel de cada indivíduo

\footnotetext{
7 Lei Brasileira de Inclusão da Pessoa com Deficiência - Art. $2^{\circ}$ Considera-se pessoa com deficiência aquela que tem impedimento de longo prazo de natureza física, mental, intelectual ou sensorial, o qual, em interação com uma ou mais barreiras, pode obstruir sua participação plena e efetiva na sociedade em igualdade de condições com as demais pessoas. (Brasil, 2015)

${ }^{8}$ Sobre trabalho como princípio educativo Rosa \& Aquino (2019).
} 
envolvido para atuar de forma adequada a cada situação; assim como consiga trabalhar com o lúdico e evitar os acidentes domésticos e prevenção aos maus tratos a criança.

Diante do exposto conclui-se que curso de cuidador é uma ferramenta importante de implementação do objetivo de desenvolvimento sustentável, a formação inicial continuada de jovens e adultos e fortalecimento de uma rede de proteção social pautados na prevenção e promoção dos diretos humanos.

\section{Considerações Finais}

A pesquisa de mapeamento de demandas e as oportunidades realizadas com os 30 CRAS apontou os principais cursos de qualificação profissional que a população que acessa os serviços de assistência social procuram na cidade do Rio de Janeiro.

Conclui-se que o trabalho de gestão da rede socioassistencial na Proteção Social Básica é muito importante para trabalhar a matricialidade sociofamiliar e a territorialização.

A territorialização aumentaria a eficácia e efetividade de projetos sociais de prevenção ou enfrentamento das situações de pobreza e extrema pobreza, assim como e designar e formular para que os serviços socioassistenciais mais próximos das necessidades sociais e perceber as potencialidades locorregionais. Para uma gestão territorial efetiva é necessário um conhecimento do território, da organização e articulação de instituições sociais de cada microterritório referenciados desta forma gerenciar e acompanhar os usuários do SUAS. Ao mesmo tempo fornecer informações e dados para o gestor municipal para subsidiar, a elaboração do Plano Municipal de Assistência Social; processo de formação e qualificação da equipe de referência. (Labra, 1999) e Martins (2003).

Cabe também destacar que o SUAS identifica o território como espaço humano habitado, marcada pelas pessoas que vivem, espaços coletivos, expressão de solidariedade, relações familiares não somente definida por consanguinidade, fortalecimento das relações de vizinhanças, vínculo de pertença e de identidade. Também marcado com desigualdades econômicas e sociais, por conflitos armados na guerra ao varejo de drogas, que marcam cotidianamente a vida dos moradores de favelas.

O destaque deste artigo foi apresentar o principal curso escolhido pelos CRAS no eixo ambiente e saúde, diante do exposto enfatizar que não cabe ao CRAS a oferta de cursos de formação de qualificação profissional, porque estes cursos devem ser oferecidos em parceria com instituições certificadoras e formadoras na área educacional. Para tanto, verifica-se a necessidade de estudar os outros eixos de formação inicial continuada. Conclui-se que parceria institucional deveria ser uma prioridade no que tange a programas e projeto de inclusão produtiva nas periferias e favelas. Principalmente, na cidade do Rio de Janeiro.

Por conseguinte, depreende-se que a temática da inclusão produtiva está estritamente vinculada em políticas sociais de integração social e também de inserção social. Entende-se como política de integração social aquelas as políticas sociais públicas que visam integrar o trabalhador no mercado de trabalho, oriundas de um pacto socialdemocrata entre capital $\mathrm{x}$ trabalho no sistema de acumulação capitalista, onde o trabalho tem tido uma subsunção formal e real ao capital, ao mesmo tempo estas políticas são importantes para manutenção da vida dos trabalhadores, particularmente dos moradores da periferia e favelas.

Em suma, a dinâmica da inclusão produtiva na assistência social requer mais estudos e pesquisas, principalmente para identificar a formação de núcleos de inovação e de trabalho na particularidade das favelas cariocas.

\section{Agradecimentos}

Agradecemos a todos que diretamente e indiretamente contribuíram para a realização e sucesso do artigo. 


\section{Referências}

Alvito, M., \& Zaluar. A ( org). (2004). Um século de favela. Editora FGV.

Araujo, L. A. D. (1999) A proteção constitucional das pessoas portadoras de deficiência. Publicação oficial da Coordenadoria Nacional para Integração da Pessoa Portadora de Deficiência - CORDE. Brasília.

Brasil, (2012). Programa Nacional de Promoção do Acesso ao Mundo Trabalho - ACESSUAS-TRABALHO. Resolução n 18 de 24/05/2012 / CNAS Conselho Nacional de Assistência Social. Diário Oficial da União de 25/05/2012

Brasil, (2014) Caderno de Orientações de Técnicas Programa Nac ional do Acesso ao Mundo do Trabalho - Acessuas Trabalho. Coordenação Departamento de Proteção Social Básica. Secretaria Nacional de Assistência Social. Ministério do Desenvolvimento Social e Combate a Fome. Governo Federal., http://www.mds.gov.br/webarquivos/publicacao/brasil_sem_miseria/Acessuas.pdf

Brasil, (2015). Lei Brasileira de Inclusão da Pessoa com Deficiência (Estatuto da Pessoa com Deficiência). Lei № 13.146, de 06 de julho de 2015, http://www.planalto.gov.br/ccivil_03/_ato2015-2018/2015/lei/113146

Brasil, (2018). Lei Geral de Proteção de Dados Lei № 13.709, de 14 de agosto de 2018, from http://www.planalto.gov.br/ccivil_03/_ato20152018/2018/lei/113709.htm.

Brasil, (2020). Nações Unidas. Objetivos do Desenvolvimento Sustentável, https://brasil.un.org/pt-br/sdgs

Brasil, (2020). Catálogo Nacional de Cursos de Técnicos e de Formação Inicial Continuada (FIC) do Ministério da Educação no ano de 2020. http://portal.mec.gov.br/cursos-da-ept/formacao-inicial-e-continuada-ou-qualificacao-profissional.

Boschetti, I. (2006) Seguridade Social e Trabalho: paradoxos na construção das políticas de previdência e assistência social no Brasil. Brasília: UNB, p. 6998.

Brasil, Ministério da Saúde (2008). Guia prático do cuidador . Ministério da Saúde, Secretaria de Atenção à Saúde, Secretaria de Gestão do Trabalho e da Educação na Saúde. - Brasília : Ministério da Saúde, 2008. 64 p. : il. - (Série A. Normas e Manuais Técnicos)

Burgos, M., Pereira, L. F. Al. Cavalcanti. M., Brum, M. \& Amoroso, M. (2012). O efeito UPP na percepção dos moradores das favelas. Desigualdade \& Diversidade (PUCRJ), 11, 49-97.

Harvey, D.(2013). O Enigma do Capital. Editora Xamã. Ano 2013.

Dutra, V. C. A. Notas sobre ética e desenvolvimento sustentável no mundo contemporâneo. (2016) Universidade Veiga de Almeida, 2016. 1. 157p.

Dutra, V. C. A., Mesquita, A. A., \& Assis, J. F. (Org.) (2017). Serviço Social, Formação Profissional e Política Social: Questões Contemporâneas. Editora Gramma, v. 200. 250p.

Dutra, V. C. A. (2016) Assistência Social e Inclusão Produtiva. In: Centro de Capacitação da Política de Assistência Social. (Org.). Gestão do Sistema Único de Assistência Social: questões contemporâneas. Gráfica Expresso, 1, 01-251

Honorato, C. T. (2012) O assistente social e as favelas (1945-64). In: Mello, M. S \& Silva, L. A. M \& Freire, L; L \& Simões, S.S. (org.). Favelas cariocas ontem e hoje. Garamond/FAPERJ/Le Metro, 1, 7-519.

Labra, M. E. (1999). Análise de Políticas, Modos de Policy-Making e Intermediação de interesses: uma Revisão. Physis: Rev. Saúde Coletiva, Rio de Janeiro. $9(2): 131-166$.

Leeds, A., \& Cavalcanti, M (2018). Quanto vale uma favela | Economia, trabalho e a produção da cidade na vida cotidiana. Sociologia e Antropologia, 08, 831-848.

Lima, N. T., \& Viana, R. A. (2018). Entre latifúndios e favelas: O Brasil urbano no pensamento de Anthony Leeds. Sociologia e Antropologia. v.08.03:771805 .

Lima, A. A. B. \& Lopes, F. A. M. Diálogo social e qualificação profissional: experiências e propostas. MTE, SPPE, DEQ, 39 p. - (Construindo diálogos; v. 1). Coleção Qualificação Social e Profissional.

Machado, L. A. S. Cavalcanti, M., Motta, E., \& Araújo, M. C. S. (2018). O mundo popular: trabalho e condições de vida. Papéis Selvagens, 1. 227 p.

Martins, J. de S. (2003). A sociedade vista do abismo: novos estudos sobre exclusão, pobreza e classes sociais. Vozes.

Mello, M. A. S. Machado, L. A. S., Freire, L. L., \& Simões, S. S. (2012). Favelas Cariocas: ontem e hoje. Garamond/Faperj/Le Metro

Rosa, A. H., \& Aquino, F. J. A. (2019) A negação da identidade do trabalho como princípio educativo: um olhar profundo sobre o sentido histórico do trabalho diante da política do capital. Research, Society and Development, 8(7), e27871133, 10.33448/rsd-v8i7.1133. https://rsdjournal.org/index.php/rsd/article/view/1133.

Valladares, L. P. (2005). A invenção da favela - Do mito de origem da favela. Ed. Fundação Getúlio Vargas,204 p.

Souza, F. V. F. (2013). Assistência social e inclusão produtiva: algumas indagações. O Social em Questão - Ano XVII - nº 30.

Silva, L. A. M. (2008). Vida sob cerco: violência e rotinas nas favelas do Rio de Janeiro. FAPERJ/Nova Fronteira, 316 p. 